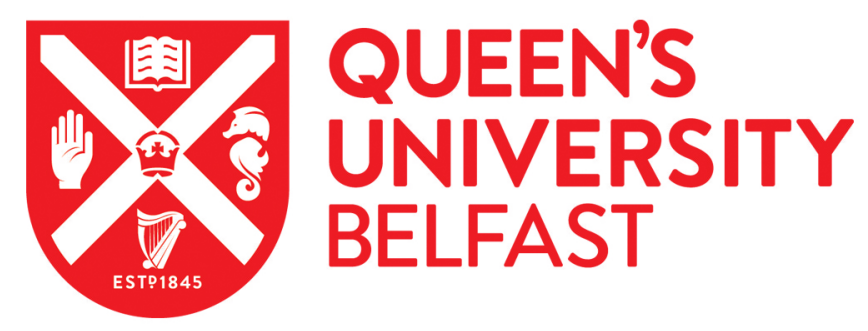

\title{
Factors associated with serum 25-hydroxyvitamin D concentrations 4 in older people in Europe: the EUREYE study
}

Casey, C., Woodside, J. V., McGinty, A., Young, I. S., McPeake, J., Chakravarthy, U., Rahu, M., Seland, J., Soubrane, G., Tomazzoli, L., Topouzis, F., Vioque, J., \& Fletcher, A. (2018). Factors associated with serum 25hydroxyvitamin D concentrations 4 in older people in Europe: the EUREYE study. European Journal of Clinical Nutrition. https://doi.org/10.1038/s41430-018-0353-1

Published in:

European Journal of Clinical Nutrition

Document Version:

Peer reviewed version

Queen's University Belfast - Research Portal:

Link to publication record in Queen's University Belfast Research Portal

Publisher rights

(c) 2018 The Authors. This work is made available online in accordance with the publisher's policies. Please refer to any applicable terms of use of the publisher.

\section{General rights}

Copyright for the publications made accessible via the Queen's University Belfast Research Portal is retained by the author(s) and / or other copyright owners and it is a condition of accessing these publications that users recognise and abide by the legal requirements associated with these rights.

Take down policy

The Research Portal is Queen's institutional repository that provides access to Queen's research output. Every effort has been made to ensure that content in the Research Portal does not infringe any person's rights, or applicable UK laws. If you discover content in the Research Portal that you believe breaches copyright or violates any law, please contact openaccess@qub.ac.uk. 
Factors associated with serum 25-hydroxyvitamin D concentrations in older people in Europe: The EUREYE study

Running head: Serum 25OHD and related factors.

Claire Casey ${ }^{1}$, Jayne V. Woodside ${ }^{1, *}$, Ann McGinty ${ }^{1}$, Ian S. Young ${ }^{1}$, Jennifer McPeake ${ }^{1}$, Usha Chakravarthy $^{2}$, Mati Rahu ${ }^{3}$, Johan Seland $^{4}$, Gisèle Soubrane ${ }^{5}$, Laura Tomazzoli ${ }^{6}$, Fotis Topouzis $^{7}$, Jésus Vioque ${ }^{8}$, A.E. Fletcher ${ }^{9}$

1-Centre for Public Health, Queen's University Belfast, Belfast, Northern Ireland

2- Department of Ophthalmology, Queen’s University Belfast, Belfast, Northern Ireland

3- Department of Epidemiology and Biostatistics, National Institute for Health Development, Tallinn, Estonia

4-Eye Department, University of Bergen, Bergen, Norway

5-Department of Ophthalmology, Hotel Dieu de Paris, University Paris Descartes, France

6-Clinica Oculistica, Università degli Studi di Verona, Italy

7-Department of Ophthalmology, Aristotle University of Thessaloniki School of Medicine, Greece

8-University Miguel Hernandez, Ciberesp, Isabial-Fisabio, Alicante, Spain

9- Faculty of Epidemiology and Population Health, London School of Hygiene \& Tropical Medicine, London, UK

*Corresponding author: J.V. Woodside, Email j.woodside@qub.ac.uk 


\begin{abstract}
Background/Objective: We aimed to describe serum 25-hydroxyvitamin D (25OHD) concentrations in older Europeans and to investigate associations between 25OHD and lifestyle factors, including dietary intake and supplement use.
\end{abstract}

Subjects/Methods: Men and women aged $\geq 65$ years were recruited from seven centres across north to south Europe. Serum $25 \mathrm{OHD}_{2}$ and $25 \mathrm{OHD}_{3}$ concentrations were measured by liquid chromatography tandem mass spectrometry (LC-MS/MS) in 4495 samples and total 25OHD $\left(25 \mathrm{OHD}_{2}+25 \mathrm{OHD}_{3}\right)$ was adjusted for season of blood collection.

Results: The mean $\left(25^{\text {th }}, 75^{\text {th }}\right.$ quartile $)$ of seasonally adjusted $25 \mathrm{OHD}$ was $46(34,65)$ $\mathrm{nmol} / \mathrm{L}$, with the highest concentration of $25 \mathrm{OHD}$ in Bergen $[61(49,79) \mathrm{nmol} / \mathrm{L}]$, and the lowest in Paris $[36(24,57) \mathrm{nmol} / \mathrm{L})]$. Vitamin D deficiency $(25-50 \mathrm{nmol} / \mathrm{L})$ and vitamin D insufficiency $(50-75 \mathrm{nmol} / \mathrm{L})$ were found in $41 \%$ and $33 \%$ of the population, respectively. In multivariable analysis controlled for confounders, seasonally adjusted 25OHD concentrations were significantly $(\mathrm{p}<0.05)$ lower in smokers and participants with self-reported diabetes and higher with increasing dietary vitamin D, and supplement use with fish liver oil, omega-3 and vitamin D. Additionally in further analysis excluding Bergen, 25OHD was associated with higher intakes of oily fish and increasing UVB exposure. We observed low concentrations of 25OHD in older people in Europe.

Conclusions: Our findings of the higher 25OHD concentrations in supplement users (omega3 fish oil, fish liver oil, vitamin D) add to current recommendations to reduce vitamin D deficiency. We were unable to fully assess the role of dietary vitamin D as we lacked information on vitamin D fortified foods. 


\section{Introduction}

Vitamin D deficiency $(<50 \mathrm{nmol} / \mathrm{L})$ is highly prevalent in older people (1-4). Serum 25hydroxyvitamin D (25OHD) concentrations in Central Europe can vary from 32.5 to 72.5 $\mathrm{nmol} / \mathrm{L}$, with seasonal variability present (5). The main source of vitamin $\mathrm{D}$ is the endogenous production of vitamin $\mathrm{D}_{3}$ from sunlight (6). However, seasonal and latitudinal effects in Europe can reduce the production of vitamin $\mathrm{D}_{3}$ from the sun (7-10). The main sources of dietary vitamin D are oily fish and eggs $(11,12)$, however, eggs despite being considered an important source of vitamin $\mathrm{D}$, have a relatively low dietary vitamin $\mathrm{D}$ content. There is also evidence to suggest meat may be a vital source of dietary vitamin D (13). Social isolation and reduced mobility, both of which can lead to a decrease in the time spent outdoors, has been suggested as a reason for lower concentrations of total 25OHD (Total $\left.25 \mathrm{OHD}=25 \mathrm{OHD}_{2}+25 \mathrm{OHD}_{3}\right)$ in older individuals (14). Effective dietary strategies, including supplements, have been recommended by a number of research organisations and research groups for an older population group (15-17). 40-100 micrograms of supplement vitamin D has been suggested in addition to safe UVB exposure. This particular group have suggested vitamin D deficiency be defined as $<50 \mathrm{nmol} / \mathrm{L}, 50-75 \mathrm{nmol} / \mathrm{L}$ as suboptimal and $75-125 \mathrm{nmol} / \mathrm{L}$ as optimal vitamin D concentration (18). It has also been suggested that target vitamin D concentrations and recommended vitamin D supplement values should be age-, body weight-, disease status- and ethnicity-dependent rather than focused on age alone. In addition, the recommendations should also depend on one's individual health outcome concerns, latitude of residence, dietary and cultural habits. This would ensure national/international guidelines would be more applicable to clinical practices (19).

There is a large amount of variability in the literature regarding $25 \mathrm{OHD}$ concentrations in different countries(20-23). The use of different assays and discrepancies over the definition of vitamin D deficiency makes the comparison of literature from various countries and in 
different population groups difficult. A recent paper by Cashman and colleagues tried to address this issue by applying vitamin D standardization program (VDSP) protocols to existing 25OHD data from 55844 participants from representative studies for European children, teenagers, adults and older adults. The authors concluded that vitamin D deficiency (defined as $<30 \mathrm{nmol} / \mathrm{L}$ ) was highly prevalent in Europe, with $13 \%$ of individuals being deficient throughout the year. Deficiency throughout the winter months (November to March) was $18 \%$, and $8 \%$ in the summer months (April-October)(21).

The European Eye (EUREYE) study was a cross-sectional study of older people from centres in seven countries spanning north to south Europe, originally set up to investigate risk factors for age-related macular degeneration. In previous analyses we reported the association between vitamin D deficiency and age-related macular degeneration (24) and total 25OHD concentrations and myopia (25) .In the present analysis, we aimed to further describe 25OHD concentrations, including prevalence of vitamin D deficiency, and to investigate the association of key demographic, clinical and lifestyle factors, including dietary factors, with 25OHD concentrations. 


\section{Research materials and methods}

The methods for the EUREYE study have been published in detail elsewhere (26). Briefly, participants were recruited during 2001 and 2002 by random sampling of the population aged 65 years and older in seven centres: Bergen, Norway; Tallinn, Estonia; Belfast, Northern Ireland; Paris, France; Verona, Italy; Thessaloniki, Greece; and Alicante, Spain. Over 11000 people were invited, of whom 5040 participated (45\% response rate) (27). The response rate ranged from $35 \%$ (Verona) to $59 \%$ (Tallinn), in men (50\%) compared to women $(42 \%)$ and in the age group 65-74 (48\%) compared to those 75 years and over (39\%). Written informed consent was obtained from all study participants. Ethical approval was obtained for each centre from the relevant ethics committee and the research adhered to the tenets of the Declaration of Helsinki.

Participants were interviewed at the research clinic in each centre on a one to one basis by trained fieldworkers using a structured questionnaire. Information including age, smoking, alcohol use, previous cardiovascular events (angina, stroke, and heart attack) or history of diabetes mellitus, diet and sunlight exposure was obtained. Details of the diet (28) and sunlight questionnaires (29) have been described elsewhere and are summarised briefly here.

The UK European Prospective Investigation into Cancer and Nutrition (EPIC) study food frequency questionnaire (FFQ) (30) was used and modified in non-UK centres to include additional food items or local varieties of a food item. The intake of oily and white fish was asked about separately. Information on supplement use was recorded. Quantification of dietary intake of vitamin D was based on food sources alone, as the FFQ was not designed to facilitate the quantification of vitamin D intake from the diet via food fortification. Nutrient intake including vitamin $\mathrm{D}$ was estimated using the food-composition tables from the $5^{\text {th }}$ edition of McCance and Widdowson's "The Composition of Foods" (31). Dietary vitamin D 
was adjusted for total energy intake using the residual model (32). We used a sunlight questionnaire to ask about place of residence and time spent outdoors between the hours of 9 a.m. and 5 p.m. and between 11 a.m. and 3 p.m daily. Estimates of exposure for different wavelengths of light (UVA, UVB and blue light) were generated from questionnaire data along with estimates from published sources that take into account time of day, month, and latitudinal variations modified by cloud cover and terrain. In these analyses we used middle of the day estimates for UVB as this is the period when sun exposure is at its highest.

At the clinical exam, systolic and diastolic blood pressure, weight and demispan were measured and a non-fasting blood sample collected from each participant. Blood samples were separated within 4 hours of collection and serum stored at $-20^{\circ} \mathrm{C}$ for up to 4 weeks before being transferred to a single laboratory (Queens University Belfast) for storage at $-80^{\circ}$ C.

The full procedure for the measurement of $25 \mathrm{OHD}_{2} / 25 \mathrm{OHD}_{3}$ has been published elsewhere (33). Briefly, serum samples were prepared using a liquid-liquid extraction technique. Working standards and quality control samples were prepared by diluting commercially available $25 \mathrm{OHD}_{2}$ and $25 \mathrm{OHD}_{3}$ bi-level serum controls (Chromsystems, Munchen, Germany) into horse serum (Sigma- Aldrich Co Ltd, Poole, UK). A d6-25OHD 3 internal standard was used in both standards and serum samples. Samples were analysed for $25 \mathrm{OHD}_{2}$ and $25 \mathrm{OHD}_{3}$ by liquid chromatography tandem mass spectrometry (LC-MS/MS) [Waters ${ }^{\circledR}$ Xevo TQ-S ${ }^{\circledR}$ \& ACQUITY UPLC (Waters Corporation, Milford, MA, USA)]. The intraassay precision ranged from $1.6-3.6 \%$ and $1.1-4.0 \%$ for $25 \mathrm{OHD}_{2}$ and $25 \mathrm{OHD}_{3}$, respectively. The inter-assay precision ranged from $1.2-5.7 \%$ and $1.2-3.0 \%$ for $25 \mathrm{OHD}_{2}$ and $25 \mathrm{OHD}_{3}$, respectively. These measurements took place on the stored samples some 8 to 10 years after initial collection. 
Statistical analysis

Statistical analysis was carried out using STATA 14 (StataCorp, College Station, TX, USA.). Normal distribution of variables was tested using normality plots and, subsequently, dietary vitamin $\mathrm{D}$ and total $25 \mathrm{OHD}\left(25 \mathrm{OHD}_{2}+25 \mathrm{OHD}_{3}\right)$ were logarithmically transformed. Season was defined by the date of blood collection as winter (December, January, February), spring (March, April, May), summer (June, July, August) and autumn, (September, October, November). Season was accounted for using sine wave analysis using the month of blood collection. Analysis using 25OHD was seasonally adjusted where required. Serum 25OHD was defined as grossly deficient $(<25 \mathrm{nmol} / \mathrm{L})$, deficient $(25-50 \mathrm{nmol} / \mathrm{L})$ and insufficient (50.75 nmol/L) as per published guidelines (16).

Seasonally adjusted total 25OHD concentrations were compared between two categories using an independent samples $t$ test. For more than two categories, ANOVA was used. Categorical variables were compared using chi-square analysis. Variables were entered into multivariate analysis if their p-value was less than 0.05 in the univariate analysis. Multiple linear regressions were used to determine factors which were independently associated with $25 \mathrm{OHD}$ by adding the variables into a general linear model. Beta coefficients and $95 \%$ confidence intervals (CI) in the multivariable analysis are reported.

Study design (7 centres) was accounted for by using the STATA survey command in the estimation of means, corresponding $\mathrm{p}$ values and 95\% CI. Design-adjusted Pearson chisquare tests were used for comparing categorical variables with categorical variables and design-adjusted Wald tests were used for comparing continuous variables with categorical variables.

As $25 \mathrm{OHD}$ and dietary vitamin D were log-transformed, mean and 95\% CI were presented as geometric mean and $25^{\text {th }}-75^{\text {th }}$ quartiles. Pearson correlation coefficients and the multiple 
regression coefficients which used a logged variable as a dependent variable were back transformed. 


\section{Results}

Blood samples were available for 4704 participants (93.4\%), of who 191 had no information on date of blood collection. A further 18 participants with total $25 \mathrm{OHD}$ concentrations greater than $150 \mathrm{nmol} / \mathrm{L}$ (11 due to implausibly high $25 \mathrm{OHD}_{2}$ values) were excluded, leaving a final sample of 4495 available for analysis.

Demographic and lifestyle characteristics of study participants are presented in Table 1 . The mean age was similar across the seven centres ( 71 to 74 years). UVB exposure was lower in north European centres compared to southern European centres. Paris had the lowest UVB exposure and Thessaloniki the highest. The BMI of participants in the normal (18.5-25.0 $\left.\mathrm{kg} / \mathrm{m}^{2}\right)$, overweight $\left(>25.0 \mathrm{~kg} / \mathrm{m}^{2}\right)$, and obese $\left(>30.0 \mathrm{~kg} / \mathrm{m}^{2}\right)$ categories varied across the centres. Prevalence of obesity ranged from $19.8 \%$ in participants from Belfast to $51.0 \%$ in Thessaloniki. Similarly, the prevalence of self-reported diabetes was highest in Thessaloniki (23.4\%). Current smoking status varied among the centres, Paris had the lowest percentage of smokers $(8.2 \%)$, with Thessaloniki and Bergen having twice as many (18.3 and 18.1\%, respectively) compared to Paris. The use of fish liver oil or, omega-3 fish oil and vitamin D supplements varied across the centres: Bergen had the highest number of omega-3 supplement users (43.7\%), and Belfast for fish liver oil (24.3\%). The remaining centres had extremely low intakes of fish liver oil or omega-3 supplement use, for example, Alicante had no supplement users. Vitamin D supplement use was low in the seven study centres, with Bergen having the highest percentage of supplement users $(3.9 \%)$, and Thessaloniki having no users of vitamin D supplements.

Figure 1 shows the comparison of $25 \mathrm{OHD}$ concentrations by season overall and by centre. Overall, participants whose blood were collected between December and May had significantly lower 25OHD concentrations compared to those collected between June and 
November (41 and $51 \mathrm{nmol} / \mathrm{L}$, respectively $\mathrm{p}<0.001$ ). Seasonal differences were observed between each centre $(p<0.001)$, with the exception of Bergen $(p=0.55)$.

Table 2 shows the seasonally adjusted geometric mean and $25^{\text {th }}, 75$ th quartiles for $25 \mathrm{OHD}$, prevalence of participants who were grossly deficient $(<25 \mathrm{nmol} / \mathrm{L})$, deficient $(25-50 \mathrm{nmol} / \mathrm{L})$ and insufficient $(50-75 \mathrm{nmol} / \mathrm{L})$ in $25 \mathrm{OHD}$ and dietary vitamin $\mathrm{D}$ intake by centre. Bergen had significantly higher $25 \mathrm{OHD}$ concentrations than all other centres $(61 \mathrm{nmol} / \mathrm{L})$, while the lowest 25OHD concentration was found in Paris $(36 \mathrm{nmol} / \mathrm{L})$. The proportion of vitamin D deficiency was $41 \%$ overall, and varied by centre with the lowest proportion in Bergen (26\%), and the highest in Thessaloniki (48\%). The proportion with insufficient vitamin D concentrations was 33\% overall, lowest in Paris (21\%) and highest in Bergen (44\%). Dietary vitamin D intake varied by centre, with a two-fold difference from the lowest dietary intake of vitamin D observed to the highest. Thessaloniki had the lowest intake of dietary vitamin D $(1.2 \mu \mathrm{g} /$ day $)$, whereas the highest intake of dietary vitamin D was found in Alicante (2.9 $\mu \mathrm{g} /$ day).

In univariable analysis, factors associated with seasonally adjusted 25OHD concentrations were age, sex, alcohol consumption, self-reported diabetes, oily fish intake, dietary vitamin D, supplements with fish liver oil, omega-3, and vitamin D (Table 3). In multivariable analysis, increasing age, self-reported diabetes and current smoking were associated with lower 25OHD concentrations and increasing dietary vitamin D, and supplement use with fish liver, omega-3 or vitamin D with higher concentrations of 25OHD (Table 4). Supplement use especially omega-3 was associated with the largest differences in $25 \mathrm{OHD}$ between users and non-users. There was no evidence of collinearity in the analyses between different types of supplements. The model explained $10.8 \%$ of the variance in $25 \mathrm{OHD}$ concentrations. Because of the much higher concentrations of $25 \mathrm{OHD}$ in Bergen, we carried out a further analysis excluding participants from Bergen and dropping omega-3 and vitamin D supplement use 
(since few participants outside the Bergen centre used these supplements). In this model, age, diabetes and smoking remained significantly associated with lower 25OHD concentrations and, in addition to fish liver oil supplement, oily fish consumption $>2$ portions/week and UVB exposure were associated with higher 25OHD concentrations (Table 4). Results for dietary vitamin D were slightly attenuated compared to the previous model including Bergen. This model explained $7.2 \%$ of the variance in $25 \mathrm{OHD}$ concentrations. Differences in 25OHD were similar to those reported in the previous model including Bergen, for example around $5 \mathrm{nmol} / \mathrm{L}$ lower in participants with diabetes compared to participants with no reported diabetes in both models and $9 \mathrm{nmol} / \mathrm{L}$ higher with fish oil supplement use. 


\section{Discussion}

Our study confirms findings from studies of European populations of low 25OHD concentrations and high proportions with vitamin D deficiency or insufficient levels (21). We observed that for serum $25 \mathrm{OHD}$ concentrations there was no north to south gradient, as would perhaps have been expected for vitamin D. Lower concentrations of vitamin D were expected in more northerly centres due to reduced UVB exposure during the year compared to more southern countries. Bergen despite its geographical location as one of the most northerly located had the highest level of $25 \mathrm{OHD}$ and the lowest prevalence of vitamin $\mathrm{D}$ deficiency. This finding has also been observed in other observational studies and systematic reviews $(20,21,34,35)$. Hilger and colleagues investigated global $25 \mathrm{OHD}$ concentrations in several countries and age groups in a systematic review. While global 25OHD concentrations were approximately $53 \mathrm{nmol} / \mathrm{L}$, it was observed in sub-analysis that older people in Sweden had comparatively higher 25OHD concentrations than any other older population in Europe (20). It can be hypothesised that Sweden and Norway would have similar dietary and cultural practices in addition to similar UVB exposure. Cashman and colleagues reported, based on 14 European population-based studies, that, in both adults and older adults, the prevalence of vitamin D deficiency was lower in more northerly latitude countries, such as Norway, Finland and Iceland, whereas countries in central Europe had a higher prevalence of vitamin D deficiency (21). It has been hypothesised that the high levels of $25 \mathrm{OHD}$ observed in Norway may be due to the high consumption of fish and food fortification of basic food items $(34,35)$. Comparable to the current study, O'Neill and colleagues observed higher 25OHD concentrations in northern European countries, compared to central Europe during the winter months (36). The high proportion of omega-3 fish oil supplement users in Bergen (44\%) is likely to be one of the sources of the high 25OHD concentrations. It is also notable that fish oil ,which is the likely source of vitamin D in the Norwegian population, is considered a food 
rather than a supplement (37). Omega-3 fish oils were strongly associated with seasonally adjusted 25OHD despite these supplements not containing vitamin D. We hypothesise but cannot confirm that the omega-3 fish oils consumed by participants in Bergen could be fortified with vitamin D. The use of omega-3 fish oil supplements was low in all other centres in the current study; in contrast fish liver oil supplement was more common in Belfast (24\%). However the participants in the Bergen sample may have other characteristics that are associated with increased production of $25 \mathrm{OHD}_{3}$ concentrations through UVB exposure such as paler skin (38). In contrast, Paris with the lowest 25OHD concentrations and the highest proportion of vitamin D deficiency had the lowest UVB exposures probably reflecting the lifestyle of a central urban population.

Age was negatively associated with $25 \mathrm{OHD}$ concentrations. Ageing can have a substantial effect on 25OHD concentrations. This is predominantly due to the reduced dermal capacity of older indivduals to produce vitamin $\mathrm{D}_{3}$. The capacity of the skin to produce vitamin $\mathrm{D}_{3}$ is approximately $75 \%$ less in an older indivdual ( $>65$ years) compared to an average 25 year old being exposed to the same amount of UVB radiation $(39,40)$. Decreasing concentrations of 25OHD with increasing age may also be due to a change in behaviours, for example, older individuals tend to be outside less due to decreased ability to do physical activity and may wear more concealed clothing compared to their younger counterparts (41).Van Schoor and colleagues observed in a younger cohort (average age $60 \pm 3.0$ years; $n=738$ ) that, for every year increase, $25 \mathrm{OHD}$ increased by $0.6 \mathrm{nmol} / \mathrm{L}$, whereas in the older cohort (average age 76.0 \pm 6.7 years; $n=1320$ ), it was observed that for every year increase in age, $250 H D$ decreased by $1.0 \mathrm{nmol} / \mathrm{L}(42)$.

Smoking was negatively associated with serum 25OHD in the current study. This is in line with a study from a Danish population of 510 perimenopausal women aged $45-58$ years. $50 \%$ of study participants were current smokers, and it was observed that smoking significantly 
decreased serum 25OHD (43). Additionally, in a study of 612 older men of which $31 \%$ were current smokers, current smokers had significantly lower vitamin D than those who never smoked. This association showed a dose-response relationship (44). The method by which smoking influences serum 25OHD is currently unknown, and difficult to determine due to the large number of toxic chemical compounds. There is evidence to suggest that smokers have altered hepatic function (45), and therefore could influence 25OHD concentrations.

Dietary vitamin D intake in the current study was below the recommended adequate intake (AI) for European adults as set by the European Food Safety Authority (EFSA) (46). EFSA suggests that the AI for adults ( $>18$ years of age) should be $15 \mu \mathrm{g} /$ day. The highest observed intake of dietary vitamin D in the current study was in Alicante $(2.9 \mu \mathrm{g} /$ day $)$, and the overall average for the total population was $2.0 \mu \mathrm{g} /$ day. In contrast, the European Prospective Investigation into Cancer and Nutrition (EPIC) study observed a north/south gradient for dietary vitamin D intakes. The highest dietary vitamin D intake was observed in Sweden (7.6 $\mu \mathrm{g} /$ day $)$, with the lowest observed in Italy $(1.9 \mu \mathrm{g} /$ day $)$. Overall, the average dietary vitamin D intake across Europe in the EPIC study was $4.2 \mu \mathrm{g} /$ day (47). While these intakes are still below the AI for European adults, they are higher than observed in the current study. This may be due to the inability of our dietary analysis to quantify dietary vitamin D from fortified foods. Fortified foods are an important source of dietary vitamin D in several countries. Mandatory fortification with vitamin D of margarine, butter and one type of skimmed milk is employed in Norway(48). Up until 2013 the UK had mandatory fortification of margarine with vitamin D, the current study was conducted between 2001-2002, and therefore margarine was subject to fortification. Voluntary fortification is also in use in the UK and France for food items such as dairy foods, cereals and vegetable oils $(17,49)$. The remaining centres (Estonia, Italy, Spain and Greece) have no formal fortification practices $(23,50,51)$. 
This could suggest that our study has been unable to identify important sources of dietary vitamin $\mathrm{D}$ in habitual diets in several centres.

Lower serum 25OHD concentrations were associated with self-reported diabetes in the current study. Only a few studies have investigated the relationship between 25OHD and diabetes in an older population. Hirani and colleagues found that in people ( $>70$ years) $25 \mathrm{OHD}$ concentrations of less than $50 \mathrm{nmol} / \mathrm{L}$ were associated with type 2 diabetes in confounder adjusted analysis $(\mathrm{OR}=1.73,95 \% \mathrm{CI}=1.04-2.86, \mathrm{p}=0.03)$. 25OHD concentrations above $50 \mathrm{nmol} / \mathrm{L}$ were not significantly associated with type 2 diabetes(52). Park and colleagues in a 12 year longitudinal study of older people observed higher 25OHD concentrations $(>75 \mathrm{nmol} / \mathrm{L})$ had a lower hazard ratio for type 2 diabetes compared to lower 25OHD concentrations. There was an inverse dose-response gradient between 25OHD concentration and risk of diabetes; each $25 \mathrm{nmol} / \mathrm{L}$ increase was associated with a 0.64 hazard ratio for diabetes (53). These findings of an association between lower 25OHD and diabetes in an older population have important implications for health. Type 2 diabetes is a growing health problem (54) and, if compounded by deficiency of vitamin D, which has important roles in bone health and immune regulation $(55,56)$, may potentially cause worse morbidity in this group. The association of $25 \mathrm{OHD}$ with type 2 diabetes is biologically plausible, as it has been suggested that vitamin D sufficiency may be required for optimal insulin action and secretion, which are two fundamental features of type 2 diabetes. The vitamin $\mathrm{D}$ receptor and $1-\alpha$-hydroxylase are both present in $\beta$-cells of the pancreas $(57,58)$. In-vitro and in-vivo studies show that vitamin $\mathrm{D}$ receptor knockout mice, had impaired glucose induced insulin secretion, and the insulin secretory response only improved after vitamin D supplementation in both animals and humans. However, a causal effect remains to be demonstrated in human studies and cannot be determined from this class of a study(59). 
The current study has several strengths and limitations. We investigated data from seven centres that spanned latitudes extending from north to south of Europe, and this encompassed a range of dietary habits and lifestyle behaviours. $25 \mathrm{OHD}_{2}$ and $25 \mathrm{OHD}_{3}$ were measured using the gold-standard method of measuring 25OHD (LC-MS/MS) using commercial calibrators and internal standards. Accuracy and precision of the assay was also maintained using the vitamin D external quality assurance system (DEQAS). The limitations of the current study include the retrospective and self-reported nature of lifestyle variables, including supplement use, smoking, alcohol, diabetes and CVD history. EUREYE had a 45\% response rate and this may have resulted in a sample that were more health conscious and therefore we may be underestimating the prevalence of vitamin D deficiency. The use of UK food tables to analyse the dietary intake of all centres is a limitation, since country-specific food tables were not available for the majority of the countries involved in the EUREYE study. Furthermore, information on vitamin D supplement use was relatively limited, with only vitamin D supplement intake being included if reported; multivitamin use that may have included vitamin D was not included use due to a lack of individual level data on the brands of supplements. Information on ethnicity and skin colour of the participants were also not available in the current study. As this is a cross-sectional observational study, we cannot conclude any casual or confirmatory effects of low 25OHD concentrations on type 2 diabetes. In conclusion, we observed low concentrations of 25OHD across Europe in an older population group, an overall vitamin D deficiency of $41 \%$ and noted the lack of a north-south gradient. Our findings of the higher 25OHD concentrations in supplement users (omega -3 fish oil, fish liver oil, vitamin D) confirm those reported in other European studies (21) and support recommendations in the UK (17) and other European countries (35) for improving 25OHD concentrations. We were unable to fully assess the role of dietary vitamin D as we lacked information on vitamin D fortified foods. 
Conflict of interest: The authors have nothing to disclose.

The European Eye (EUREYE) Study was supported by the European Commission 5th Framework (QLK6-CT-1999-02094), the Macular Disease Society UK, UK MRC Biomarkers Award (G0601354), Pocklington Trust and Guide Dogs for the Blind (OR201105d). M.R. salaried by his home institute (grant IUT5-1 from the Estonian Research Council). Additional funding in Alicante was received from the Fondo de Investigacion Sanitaria, Madrid, Spain (grants FIS 01/1692E, RCESP C 03/09), and Oficina de Ciencia y Tecnologia Generalitat Valencia, Valencia, Spain (grant CTGCA/2002/06).

UC, MR, JS, GS, LT, FT, JV and AEF designed and implemented the EUREYE study. CC, ISY, JVW, AMcG formulated the current research question, JMcP carried out the laboratory analysis, $\mathrm{CC}$ and $\mathrm{AEF}$ analyzed the data. JVW, AMcG and AEF supervised the work. CC wrote the manuscript. All authors revised the manuscript and approved the final draft. All authors have agreed to be accountable for all aspects of the work in ensuring that questions related to the accuracy or integrity of any part of the work are appropriately investigated and resolved. 
1. Forrest KYZ, Stuhldreher WL. Prevalence and correlates of vitamin D deficiency in US adults. Nutr Res. 2011;31(1):48-54.

2. Samefors M, Ostgren CJ, Molstad S, Lannering C, Midlov P, Tengblad A. Vitamin D deficiency in elderly people in Swedish nursing homes is associated with increased mortality. Eur J Endocrinol. 2014;170(5):667-75.

3. Arnljots R, Thorn J, Elm M, Moore M, Sundvall PD. Vitamin D deficiency was common among nursing home residents and associated with dementia: A cross sectional study of 545 Swedish nursing home residents. BMC Geriatr. BMC Geriatrics; 2017;17(229):1-8.

4. Sluyter JD, Camargo CA, Stewart AW, Waayer D, Lawes CMM, Toop L, et al. Effect of monthly, high-dose, long-term vitamin D supplementation on central blood pressure parameters: A randomized controlled trial substudy. J Am Heart Assoc. 2017;6(10):e006802.

5. Pludowski P, Grant WB, Bhattoa HP, Bayer M, Povoroznyuk V, Rudenka E, et al. Vitamin D status in central Europe. Int J Endocrinol. Hindawi Publishing Corporation; $2014 ; 2014$.

6. Norman AW. From vitamin D to hormone D: fundamentals of the vitamin D endocrine system essential for good health. Am J Clin Nutr. 2008 Aug;88(2):491S-499S.

7. Valtueña J, González-Gross M, Huybrechts I, Breidenassel C, Ferrari M, Mouratidou T, et al. Factors associated with vitamin D deficiency in European adolescents: the HELENA study. J Nutr Sci Vitaminol (Tokyo). 2013;59:161-71.

8. Brot C, Vestergaard P, Kolthoff N, Gram J, Hermann AP, Sørensen OH. Vitamin D status and its adequacy in healthy Danish perimenopausal women: relationships to 
dietary intake, sun exposure and serum parathyroid hormone. Br J Nutr. 2001;86(S1):S97.

9. Kroll MH, Bi C, Garber CC, Kaufman HW, Liu D, Caston-Balderrama A, et al. Temporal relationship between vitamin D status and parathyroid hormone in the United States. PLoS One. 2015;10(3):1-13.

10. Engelsen $\mathrm{O}$. The relationship between ultraviolet radiation exposure and vitamin D status. Nutrients. 2010;2(5):482-95.

11. Institute of Medicine. Dietary Reference Intakes for Calcium and Vitamin D [Internet]. Washington D.C.; 2011. Available from: https://www.ncbi.nlm.nih.gov/books/NBK56070/

12. Public Health England. McCance and Widdowson's The Composition of Foods. 7th ed. Cambridge: Royal Society of Chemistry; 2015. 252-279 p.

13. Crowe FL, Steur M, Allen NE, Appleby PN, Travis RC, Key TJ. Plasma concentrations of 25-hydroxyvitamin D in meat eaters, fish eaters, vegetarians and vegans: Results from the EPIC-Oxford study. Public Health Nutr. 2011;14(2):340-6.

14. Oudshoorn C, van der Cammen TJM, McMurdo MET, van Leeuwen JPTM, Colin EM. Ageing and vitamin D deficiency: effects on calcium homeostasis and considerations for vitamin D supplementation. Br J Nutr. 2009 Jun;101(11):1597-606.

15. EFSA Panel on Dietetic Products Nutrition and Allergies. Dietary reference values for vitamin D. 2016.

16. Holick MF, Binkley NC, Bischoff-Ferrari HA, Gordon CM, Hanley DA, Heaney RP, et al. Evaluation, treatment, and prevention of vitamin D deficiency: An endocrine society clinical practice guideline. J Clin Endocrinol Metab. 2011;96(7):1911-30. 
17. Scientific Advisory Committee on Nutrition. Vitamin D and Health [Internet]. London, United Kingdom; 2016. Available from:

https://www.gov.uk/government/publications/sacn-vitamin-d-and-health-report

18. Pludowski P, Karczmarewicz E, Bayer M, Carter GD, Chelbna-Sokół D, CzechKowalska J, et al. Practical guidelines for the supplementation of vitamin D and the treatment of deficits in Central Europe - recommended vitamin D intakes in the general population and groups at risk of vitamin D deficiency. Endokrynol Pol. $2013 ; 64(4): 319-27$.

19. Pludowski P, Holick MF, Grant WB, Konstantynowicz J, Mascarenhas MR, Haq A, et al. Vitamin D supplementation guidelines. J Steroid Biochem Mol Biol. $2018 ; 175: 125-35$

20. Hilger J, Friedel A, Herr R, Rausch T, Roos F, Wahl DA, et al. A systematic review of vitamin D status in populations worldwide. Br J Nutr. 2014 Jan;111(1):23-45.

21. Cashman KD, Dowling KG, Skrabakova Z, Gonzalez-Gross M, Valtue J, Henauw S De, et al. Vitamin D deficiency in Europe: pandemic? Am J Clin Nutr. 2016;103(4):1033-44.

22. Lips P. Worldwide status of vitamin D nutrition. J Steroid Biochem Mol Biol. Elsevier Ltd; 2010 Jul;121(1-2):297-300.

23. Spiro A, Buttriss JL. Vitamin D: An overview of vitamin D status and intake in Europe. Nutr Bull. 2014;39(4):322-50.

24. McKay GJ, Young IS, Mcginty A, Bentham GCG, Chakravarthy U, Rahu M, et al. Associations between Serum Vitamin D and Genetic Variants in Vitamin D Pathways and Age-Related Macular Degeneration in the European Eye Study. Ophthalmology. 
2016;124(1):90-6.

25. Williams KM, Bentham GCG, Young IS, McGinty A, McKay GJ, Hogg R, et al. Association Between Myopia, Ultraviolet B Radiation Exposure, Serum Vitamin D Concentrations, and Genetic Polymorphisms in Vitamin D Metabolic Pathways in a Multicountry European Study. JAMA Ophthalmol. 2017 Jan 1;135(1):47-53.

26. Augood C, Fletcher A, Bentham G, Chakravarthy U, de Jong PTVM, Rahu M, et al. Methods for a population-based study of the prevalence of and risk factors for agerelated maculopathy and macular degeneration in elderly European populations: the EUREYE study. Ophthalmic Epidemiol. 2004;11(2):117-29.

27. Augood C a, Vingerling JR, de Jong PTVM, Chakravarthy U, Seland J, Soubrane G, et al. Prevalence of age-related maculopathy in older Europeans: the European Eye Study (EUREYE). Arch Ophthalmol. 2006;124(4):529-35.

28. Augood C, Chakravarthy U, Young I, Vioque J, De Jong PTVM, Bentham G, et al. Oily fish consumption, dietary docosahexaenoic acid and eicosapentaenoic acid intakes, and associations with neovascular age-related macular degeneration. Am J Clin Nutr. 2008;88(2):398-406.

29. Fletcher AE, Bentham GC, Agnew M, Young IS, Augood C, Chakravarthy U, et al. Sunlight Exposure, Antioxidants, and Age-Related Macular Degeneration. Arch Ophthalmol. 2008;126(10):1396.

30. Bingham SA, Welch AA, McTaggart A, Mulligan AA, Runswick SA, Luben R, et al. Nutritional methods in the European Prospective Investigation of Cancer in Norfolk. Public Health Nutr. 2001;4(03):847.

31. McCance RA, Widdowson EM. McCance and Widdowson's composition of foods. 5th 
ed. London: Her Majesty’s Stationery Office; 1991.

32. Willett W, Howe G, Kushi L. Adjustment for total energy intake in epidemiologic studies. Am J Clin Nutr. 1997;65(4 Suppl):1220S-1228S.

33. Bennett SE, McPeake J, McCance DR, Manderson JG, Johnston P, McGalliard R, et al. Maternal vitamin D status in type 1 diabetic pregnancy: impact on neonatal vitamin D status and association with maternal glycaemic control. PLoS One. 2013 Jan;8:e74068.

34. Van der Wielen R, Lowik M, van den Berg H, de Groot L, Haller J, Moreiras O, et al. Serum vitamin D concentrations among elderly people in Europe. Lancet. 1995;346:207-10.

35. Lips P, Duong T, Oleksik A, Black D, Cummings S, Cox D, et al. A global study of vitamin D status and parathyroid function in postmenopausal women with osteoporosis: baseline data from the multiple outcomes of raloxifene evaluation clinical trial. J Clin Endocrinol Metab. 2001;86(3):1212-21.

36. O’Neill CM, Kazantzidis A, Ryan MJ, Barber N, Sempos CT, Durazo-Arvizu RA, et al. Seasonal Changes in Vitamin D-Effective UVB Availability in Europe and Associations with Population Serum 25-Hydroxyvitamin D. Nutrients. 2016;8(9).

37. Nordic Council of Ministers. Nordic Nutrition Recommendations 2012 [Internet]. 5th ed. Copenhagen; 2012. Available from: https://www.norden.org/en/theme/formerthemes/themes-2016/nordic-nutrition-recommendation/nordic-nutritionrecommendations-2012

38. Jablonski NG, Chaplin G. Human skin pigmentation, migration and disease susceptibility. Philos Trans R Soc B. 2012 Mar 19;367(1590):785-92. 
39. MacLaughlin J, Holick MF. Aging decreases the capacity of human skin to produce vitamin D3. J Clin Invest. 1985 Oct;76(4):1536-8.

40. Johnson MA, Kimlin MG. Vitamin D, aging, and the 2005 Dietary Guidelines for Americans. Nutr Rev. 2006;64(9):410-21.

41. Cashman KD, Wallace JMW, Horigan G, Hill TR, Barnes MS, Lucey AJ, et al. Estimation of the dietary requirement for vitamin $\mathrm{D}$ in free-living adults $\geq 64 \mathrm{y}$ of age. Am J Clin Nutr. 2009;89(5):1366-74.

42. Van Schoor N, Knol D, Deeg D, Peters F, Heijboer A, Lips P. Longitudinal changes and seasonal variations in serum 25-hydroxyvitamin D levels in different age groups: Results of the Longitudinal Aging Study Amsterdam. Osteoporos Int. 2014;25(5):1483-91.

43. Brot $\mathrm{C}$, Jorgensen NR, Sorensen $\mathrm{OH}$. The influence of smoking on vitamin D status and calcium metabolism. Eur J Clin Nutr. 1999;53:920-6.

44. Jiang CQ, Chan YH, Xu L, Jin YL, Zhu T, Zhang WS, et al. Smoking and serum Vitamin D in older Chinese people: Cross-sectional analysis based on the Guangzhou Biobank Cohort Study. BMJ Open. 2016;6(6):6-10.

45. Garcia-Esquinas E, Loeffler LF, Weaver VM, Fadrowski JJ, Navas-Acien A. Kidney Function and Tobacco Smoke Exposure in US Adolescents. Pediatrics. 2013;131(5):e1415-23.

46. EFSA NDA Panel. Scientific Opinion on Dietary Reference Values for vitamin D. EFSA Journal. 2016.

47. Jenab M, Salvini S, van Gils CH, Brustad M, Shakya-Shrestha S, Buijsse B, et al. Dietary intakes of retinol, beta-carotene, vitamin D and vitamin E in the European 
Prospective Investigation into Cancer and Nutrition cohort. Eur J Clin Nutr. 2009 Nov;63(Suppl 4):S150-78.

48. Calvo MS, Whiting SJ, Barton CN. Symposium : Vitamin D Insufficiency : A Significant Risk Factor in Chronic Diseases and Potential Disease-Specific Biomarkers of Vitamin D Sufficiency Vitamin D Intake: A Global Perspective of Current Status 1. J Nutr. 2005;25(2):310-6.

49. Dhaussy A. Vitamin D recommendations, fortification in France, and communication. Oilseeds fats Crop Lipids. 2014;21(3):2-6.

50. Kull M, Kallikorm R, Tamm A, Lember M. Seasonal variance of 25-(OH) vitamin D in the general population of Estonia, a Northern European country. BMC Public Health. 2009;9:22-9.

51. Papadakis G, Keramidas I, Kakava K, Pappa T, Villiotou V, Triantafillou E, et al. Seasonal variation of serum vitamin D among Greek female patients with osteoporosis In Vivo (Brooklyn). 2015;29(3):409-13

52. Hirani V, Cumming RG, Le Couteur DG, Naganathan V, Blyth F, Handelsman DJ, et al. Low levels of 25-hydroxy vitamin D and active 1,25-dihydroxyvitamin D independently associated with type 2 diabetes mellitus in older australian men: The concord health and ageing in men project. J Am Geriatr Soc. 2014;62(9):1741-7.

53. Park SK, Garland CF, Gorham ED, BuDoff L, Barrett-Connor E. Plasma 25hydroxyvitaminDconcentration and risk of type 2 diabetes and pre-diabetes: 12 -year cohort study. PLoS One. 2018;13(4):1-17.

54. World Health Organization. Global Report on Diabetes [Internet]. Geneva; 2016. Available from: http://www.who.int/diabetes/global-report/en/ 
55. Christodoulou S, Goula T, Ververidis A, Drosos G. Vitamin D and Bone Disease. Biomed Res Int. 2013;2013:1-6.

56. Prietl B, Treiber G, Pieber TR, Amrein K. Vitamin D and immune function. Nutrients. 2013;5(7):2502-21.

57. Bland R, Markovic D, Hills CE, Hughes S V., Chan SLF, Squires PE, et al. Expression of 25-hydroxyvitamin D3-1alpha-hydroxylase in pancreatic islets. J Steroid Biochem Mol Biol. 2004;89-90:121-5.

58. Mitri J, Pittas AG. Vitamin D and diabetes. Endocrinol Metab Clin North Am. 2014;43(1):205-32.

59. Cade C, Norman AW. Vitamin D3 improves impaired glucose tolerance and insulin secretion in the vitamin D-deficient rat in vivo. Endocrinology. 1986 Jul;119(1):84-90. 
1 Fig. 1 Comparison of total 25OHD concentrations between seasons in the EUREYE

2 population and by centre

3 25OHD, 25-hydroxyvitamin D, nmol/L, nanomole per litre

4 Results are presented as geometric mean and $25^{\text {th }}, 75^{\text {th }}$ quartiles

5 